\title{
Results of Femoral Neck Fractures Screwing in Adults at University Hospital of Brazzaville
}

\author{
Marius Monka1 ${ }^{*}$, Carine Mboutol Mandavo², Kevin Bouhélo-Pam1, Albert Ngatsé-0ko1, \\ Patrick W. H. Dakouré ${ }^{3}$, Armand Moyikoua ${ }^{1}$
}

${ }^{1}$ Service d'Orthopédie Traumatologie, CHU de Brazzaville, République du Congo

${ }^{2}$ Service de Chirurgie Pédiatrique, CHU de Brazzaville, République du Congo

${ }^{3}$ Service d'Orthopédie Traumatologie, CHU Sourô Sanou, Bobo-Dioulassou, Burkina Faso

Email: *mar_monka@yahoo.fr

How to cite this paper: Monka, M., Mandavo, C.M., Bouhélo-Pam, K., Ngatsé-Oko, A., Dakouré, P.W.H. and Moyikoua, A. (2018) Results of Femoral Neck Fractures Screwing in Adults at University Hospital of Brazzaville. Open Journal of Orthopedics, 8, 227 234.

https://doi.org/10.4236/ojo.2018.86026

Received: April 2, 2018

Accepted: June 4, 2018

Published: June 7, 2018

Copyright $\odot 2018$ by authors and Scientific Research Publishing Inc. This work is licensed under the Creative Commons Attribution International License (CC BY 4.0).

http://creativecommons.org/licenses/by/4.0/

\begin{abstract}
Purpose: The good of this survey was to analyze the epidemiological aspects and evaluate anatomical and functional results of the treatment by screwing of femoral neck fracture in adulthood at the Teaching Hospital of an underequipped country. Material and Methods: This is a retrospective study from January 1, 2011 to December 31, 2015, concerning patients hospitalized for fractures of femoral neck and having been operated by screwing. The variables studied were epidemiological and therapeutic aspects. Anatomical results were examined on standard $\mathrm{x}$ rays of the pelvis in front and the hip in profil, based on the consolidation of the bony axis. Functional results were analyzed according to the quotation of Postel Merle D'Aubigné. Results: Eleven screwings of femoral neck have been done to 11 patients ( 9 men and 2 women), average age was 47 years (29 and 60 years) from January 2011 to December 2015, at the mean recoil of 19 months (12 and 24 months). Amongst consolidated patients $(n=7)$, one patient presented a necrosis of femoral head at two years hindsight. Four patients presented an aseptic pseudarthrosis of femoral neck, or a bad anatomical result. Amidst this group of patients, one underwent a joint replacement type Moore and suggestion of intermediary prothesis was recommended to three patients. According to the quotation of Postel Merle D'Aubigné, results were very satisfactory to 5 patients, good to 2 patients and bad to 4 patients. According to the score of Parker, 7 patients presented a score of 9 and 4 patients a score of 7. Conclusion: The treatment of femoral neck fractures in adulthood requires a surgical approach by osteosynthesis and must be precocious before 24 hours in order to reduce risks of pseudarthrosis of femoral neck and necrosis of femoral head.
\end{abstract}

\section{Keywords}

Screwing, Fracture, Femoral Neck 


\section{Introduction}

Fractures of the femoral neck, appanage of the elderly are infrequent in adults under 60 years. Their incidence is in growth expansion with age due to osteoporosis and constitutes one of the main causes of death and morbidity of aged person [1]. They are for the elderly due to a mimin traumatism and for the adult often occur as a result of high-energy trauma and constitute a surgical emergency which should be performed within 12 hours [2]. The conservative surgical treatment of these fractures in adults remains the first-line treatment [3] [4] [5]. The current methods of osteosynthesis are the simple screwing and the osteosynthesis by screw plate compression type DHS (Dynamic Hip Screw). The anatomical and functional results at long-term follow-up are generally good, but the risks of necrosis of the femoral head and pseudarthrosis of the femoral neck remain present. The purpose of this work was to evaluate the anatomical and functional results of the femoral neck fracture treatment in adults in a University Hospital of an under-equipped country.

\section{Material and Methods}

\subsection{Patients}

This is a retrospective study, which focused on cases of femoral neck fractures operated by osteosynthesis through screwing, from January $1^{\text {st }} 2011$ to December $31^{\text {st }}$ 2015. It was conducted in the department of Orthopedic and Trauma surgery at the University Hospital of Brazzaville. Information was collected in logbooks and patients charts. An analytical form was established for all patients. We included patients hospitalized for femoral neck fracture operated by screwing, recoil higher or equal to 12 months and a satisfiable chart with $\mathrm{x}$ rays before and after the surgery, were excluded in this survey; patients with hip joint replacements, patients under 15, recoil less than 12 months and an incomplete medical chart. Parameters studied were holding on epidemiological and therapeutical aspects.

\subsection{Surgical Procedure}

All patients were laid down on an orthopedic table under rachianaesthesia. The procedure was performed on open hearth through Watson Jones approach to 10 patients and closed hearth under control of the image intensifier by a single incision of 3 to $4 \mathrm{~cm}$ in the femoral neck axis on the trochanteric region to one patient. The screwing of femoral neck was performed by three screws in triangle with superior base to 10 patients and two parallel screws in 1 patient. The average hospital stay was 44 days (range 20 to 110 days). Functional rehabilitation was systematic and support was allowed after 3 months of surgery.

\subsection{Evaluation Method}

The anatomical and functional evaluation was performed at an average follow-up of 19 months (extremes 12 and 24 months). 
The consolidation and the bony axis were studied on the radiographs of the pelvis face and hip profile. The functional results were analyzed according to the Parker's score [6] (Table 1) and the rating of Postel Merle D'Aubigné [7] (Table 2), which studies the pain, mobility and the walk and gives them a value from 0 to 6, allowing a global assessment of hip's function with a total of 18 marks for a normal hip. The PMA score is excellent if the score is 18 , very good if the score is 17, good if the score is between 15 and 16, average if the score is between 13 and 14, poor if the score is between 9 and 12 and bad if the score is less than 9.

\section{Results}

From January $1^{\text {st }}$ to December $31^{\text {st }} 2015$, eleven screwings of femoral neck were performed to 11 patient ( 9 men and 2 women), mean age of 47 years ( 29 and 60 years). All of them had a good anterior and autonomy a Parker score at 9 [6]. The accident of public road was the main cause $(n=6)$, followed by the fall from a high place $(\mathrm{n}=3)$ and a fall from its own height $(\mathrm{n}=2)$. Femoral neck fractures were classified according to the classification of Garden [8] (Table 3) and according to the direction of the line, we have used the biomechanic classification of Pauwels [9] (Table 4). All the eleven patients were operated by screwing.

Table 1. Parker's score (assessment of mobility before the fracture; score is the total, 0 to 9).

\begin{tabular}{ccccc}
\hline Mobility & $\begin{array}{c}\text { No } \\
\text { difficulty }\end{array}$ & $\begin{array}{c}\text { With } \\
\text { and aid }\end{array}$ & $\begin{array}{c}\text { With help } \\
\text { from another person }\end{array}$ & $\begin{array}{c}\text { Not } \\
\text { at all }\end{array}$ \\
\hline Able to get about the house & 3 & 2 & 1 & 0 \\
Able to get out of the house & 3 & 2 & 1 & 0 \\
Able to go shopping & 3 & 2 & 1 & 0 \\
\hline
\end{tabular}

Table 2. Rating of postel merle d'Aubigné.

\begin{tabular}{|c|c|c|c|}
\hline Score & Pain & Mobility & Ability to walk \\
\hline 0 & $\begin{array}{l}\text { Pain is intense } \\
\text { and permanent }\end{array}$ & $\begin{array}{c}\text { Ankylosis in } \\
\text { abnormal position }\end{array}$ & Impossible \\
\hline 1 & $\begin{array}{l}\text { Pain is severe, } \\
\text { disturbing sleep }\end{array}$ & $\begin{array}{l}\text { Ankylosis in normal } \\
\text { position or in a very } \\
\text { slight abnormal position }\end{array}$ & Only with crutches \\
\hline 2 & $\begin{array}{l}\text { Pain is severe when } \\
\text { walking, prevents } \\
\text { any activity }\end{array}$ & $\begin{array}{c}\text { Flexion }<40^{\circ} \text { (abduction }=0^{\circ} \text { ) } \\
\text { or very light joint deformity }\end{array}$ & Only with two canes \\
\hline 3 & $\begin{array}{l}\text { Pain is severe but } \\
\text { may be tolerated } \\
\text { with limited activity }\end{array}$ & Flexion $<40^{\circ}-60^{\circ}$ & $\begin{array}{c}\text { Limited with one cane } \\
\text { (less than one hour). } \\
\text { Very difficult without a cane }\end{array}$ \\
\hline 4 & $\begin{array}{l}\text { Pain only after walking } \\
\text { and disappearing with rest }\end{array}$ & $\begin{array}{c}\text { Flexion }>60^{\circ}-80^{\circ}(\text { can tie } \\
\text { shoelaces })\end{array}$ & $\begin{array}{c}\text { Prolonged with one cane; } \\
\text { limited without a cane (limp) }\end{array}$ \\
\hline 5 & $\begin{array}{l}\text { Very little pain and } \\
\text { intermittent, does not } \\
\text { preclude normal activity }\end{array}$ & $\begin{array}{c}\text { Flexion }>80^{\circ}-90^{\circ} \text {. Limited } \\
\text { abduction }\left(>25^{\circ}\right)\end{array}$ & $\begin{array}{l}\text { Without a cane } \\
\text { but slight limp }\end{array}$ \\
\hline 6 & No pain at all & $\begin{array}{c}\text { Normal. Flexion }>90^{\circ} \text {, Abduc- } \\
\text { tion }>25^{\circ}\end{array}$ & Normal \\
\hline
\end{tabular}


Table 3. Types of fractures according to Garden's classification.

\begin{tabular}{cc}
\hline Types of fractures & Effective \\
\hline Type I fracture of Garden & - \\
Type II fracture of Garden & 2 \\
Type III fracture of Garden & 4 \\
Type IV fracture of Garden & 5 \\
Total & 11 \\
\hline
\end{tabular}

Table 4. Fracture distribution by Pauwels angle.

\begin{tabular}{cc}
\hline Pauwels angle & Effective \\
\hline Angle ranged between $50^{\circ}$ and $70^{\circ}$ & 7 \\
Angle greater than $70^{\circ}$ & 4 \\
Total & 11 \\
\hline
\end{tabular}

The reduction was good in 5 patients, in 2 patients the cervico-diaphyseal angle was measured at $125^{\circ}$ and $120^{\circ}$. Seven patients consolidated first-line (Figure 1(a), Figure 1(b)). The mean period of consolidation was 7 months with extremes of 4 months and 9 months. Amongst consolidated patients, 1 presented a necrosis of femoral head class III according to Arlet and Ficat [10] classification at two years of follow-up (Figure 2(a), Figure 2(b)). Ablation of the material was performed in 2 patients after clinical and radiological consolidation. Four patients presented an aseptic pseudarthrosis of the femoral neck, a poor anatomical outcome, one of these patients had a joint replacement, type Moore (Figure 3(a), Figure 3(b)) and the indication of an intermediate prosthesis was recommended in the other three patients.

According to the rating of Postel Merle Aubigné [7], the results were considered very good in 5 patients, good in 2 patients and bad in 4 patients. On the other hand, according to the Parker score [6], 7 patients had a score of 9 and 4 patients a score of 7 .

\section{Discussion}

Our survey is limited. It is a retrospective study with a small sample. It is difficult to state from this survey the exact frequency of pathology and to have significant statistics. Our survey aimed to analyze epidemiological aspects and to assess at mean recoil of 12 months the results of anatomical and functional of the treatment by screwing of femoral neck fractures to adults at teaching hospital of Brazzaville. Concerning the epidemiological caracteristics, the profil is the one of an adult (mean age 47 years). This profil is the same to those found in the series of Swiontkowski MC and al. [11]. The male gender is comparable to Swiontkowski MC and al. [11]. The main cause was the accident of the public roads. This predominance is also found in litteracy [11]. The idea of conservative surgical treatment of femoral neck fractures aimed at preserving the femoral 


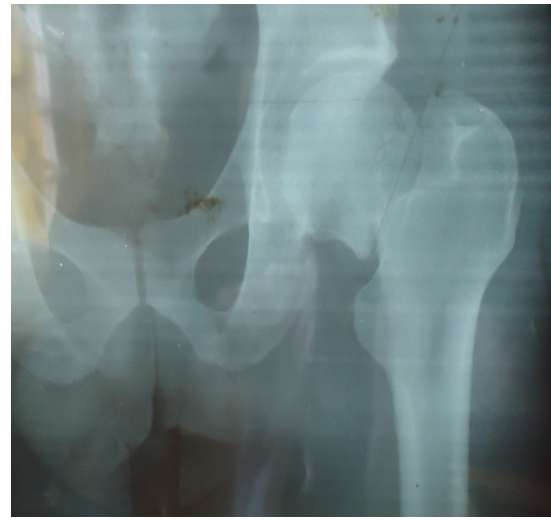

(a)

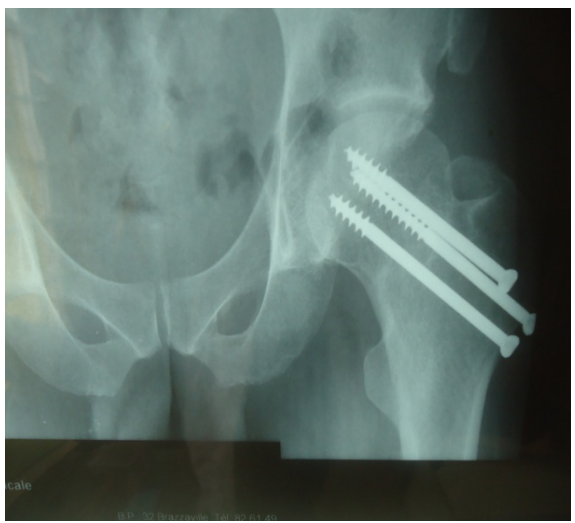

(b)

Figure 1. (a) Radiography before osteosynthesis; (b) Radiography at 2 years of osteosynthesis.

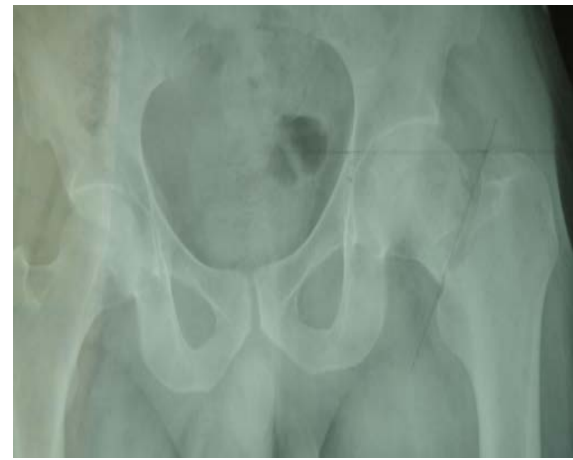

(a)

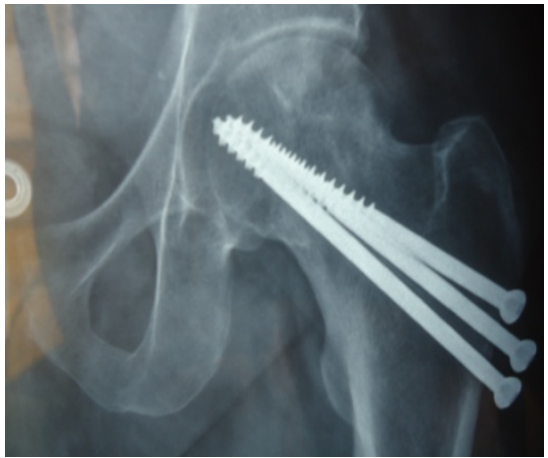

(b)

Figure 2. (a) Radiography before osteosynthesis; (b) Necrosis on screwing at 2 years recoil.

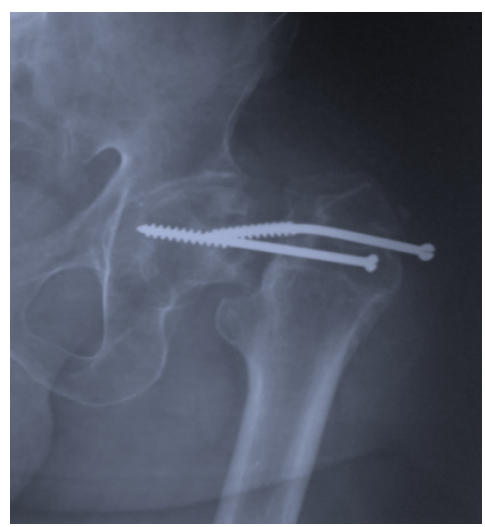

(a)

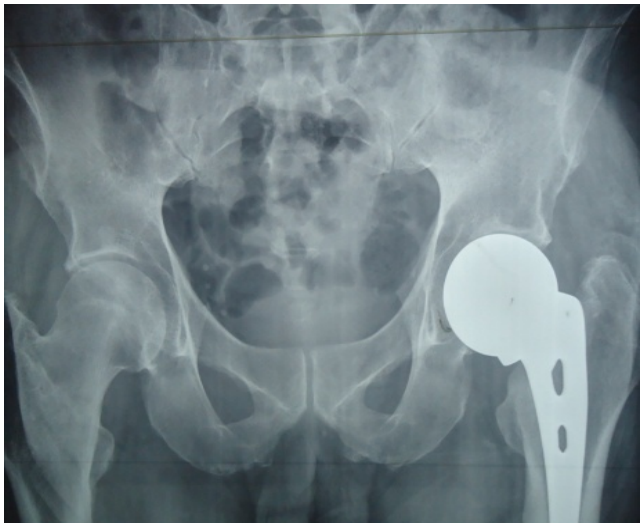

(b)

Figure 3. (a) Pseudarthrosis on femoral neck screwl; (b) Moore prothesis revision.

head was introduced by Langenbeck in 1853 [12]. Since then, many techniques have been realized: the surgical technique of screwing with a wick and a special screw derived from wooden screws in 1910 by Delbet [12], osteosynthesis by metal nail in 1931 by Smith-Petersen [13] and the osteosynthesis technique, as- 
sociated with an osteomuscular graft vascularized in 1962 by J. Judet [14]. But these techniques led to mechanical failures and failures of fracture consolidation. The advent of the image intensifier to obtain an anatomical reduction of the fracture in the years 1975 and the introduction of the screw compression plate type DHS "Dynamic hip crew" from the 1980s improved the grip in charge of fractures of the femoral neck in young subjects [12]. Despite progress in this area, conservative surgical treatment still faces two complications: aseptic necrosis of the femoral head and femoral neck nonunion, which are favored by terminal femoral head vascularization and delayed period of surgical management [4] [15]. In terms of biomechanics, the verticalization of the fracture line exposes to mechanical complications including disassembly of osteosynthesis material and femoral neck nonunion, which are seen mainly in Pauwels type II or type III fractures, known as unstable fractures [16] [17]. The risk of non-union is estimated between 5 and 35\% and the risk of necrosis between $20 \%$ and $45 \%$ [2]. In our study, the observed fractures were unstable, the permanent absence of the image intensifier and the average operative time of 35 days instead of the recommended 12 hours make the majority of our patients operated on open-focus. Despite all these constraints, the therapeutic results are considered acceptable. Our series reports 4 cases of pseudarthrosis and 1 case of necrosis of the femoral head. Femoral neck nonunion and femoral head necrosis are fairly common complications of femoral neck fracture. They are reported by several authors [2] [3] [4] [5] [15]-[20]. Perfect reduction and emergency stabilization would reduce the risk of these complications.

\section{Conclusion}

The treatment of femoral neck fractures in adults is primarily surgical by osteosynthesis and must be early before 24 hours to minimize the risk of femoral neck non-union and aseptic necrosis of the femoral head. Late delays in the surgical treatment of these fractures in our exercise conditions sometimes make it difficult to make decisions about the choice of treatment: first osteosynthesis despite the delay in therapy or intermediate hip prosthesis right away? The results obtained in our study show that the anatomical and functional prognosis can be improved despite delayed and late management.

\section{Conflict of Interests}

The authors declare that they have no competing interests.

\section{Author's Contributions}

All the authors contribute to the writing of this manuscript and have read and approved the final version.

\section{References}

[1] Keene, G.S., Parker, M.J. and Pryor, G.A. (1993) Mortality and Morbidity after Hip 
Fracture. BMJ, 307, 1248-1250. https://doi.org/10.1136/bmj.307.6914.1248

[2] Simon, P., Gouin, F., Veillard, D., et al. (2008) Fractures of the Neck of the Femur after 50 Years. Revue de Chirurgie Orthopédique et Réparatrice de 1 Appareil Moteur, 94, S108-S132. https://doi.org/10.1016/j.rco.2008.06.006

[3] Van Vugt, A.B. (2007) Femoral Neck Non-Unions: How Do I Do It? Injury, 38, S51-S54.

[4] Majernicek, M., Dungl, P., Kolman, J., Malkus, T. and Vaculik, J. (2009) Osteosynthesis of Intracapsular Femoral Neck Fractures by Dynamic Hip Screw (DHS) Fixation. Acta Chirurgiae Orthopaedicae et Traumatologiae Cechoslovaca, 76, 319-325.

[5] Karaeminogullari, O., Demirors, H., Atabek, M., et al. (2004) Avascular Necrosis and Nonunion after Osteosynthesis of Femoral Neck Fractures: Effect of Fracture Displacement and Time to Surgery. Advances Therapy, 21, 335-342. https://doi.org/10.1007/BF02850038

[6] Parker, M.J. and Palmer, C. (1993) A New Mobility Score for Predicting Mortality after Hip Fracture. Bone \& Joint Journal, 75B, 797-798.

https://doi.org/10.1302/0301-620X.75B5.8376443

[7] Merle D’Aubigné, R. (1970) Quoted Figure of the Hip. Rev Chir Orthop, 56, 481-486.

[8] Garden, R.S. (1964) Stability and Union in Subcapital Fractures of the Femur. Bone \& Joint Journal, 46, 630-647. https://doi.org/10.1302/0301-620X.46B4.630

[9] Pauwels, P. (1935) Der Schenkelhalsbruch: Ein mechanisches Problem. Grundlagen des heilungsvorganges. Prognose und Kausale Theapie. Z Orthop Chir Suppl.

[10] Arlet, J. and Ficat, P. (1972) Mode of onset of femur osteonecrosis capital primitive. Rev Chir Orthop, 35, 239-249.

[11] Swiontkowski, M.F., Winquist, R.A. and Hansen, S.T. (1984) Fractures of the Femoral Neck in Patients between the Ages of Twelve and Forty-Nine Years. The Journal of Bone \& Joint Surgery, 66, 837-846. https://doi.org/10.2106/00004623-198466060-00003

[12] Bel, J.C. and Fischer, L.P. (2011) History of Treatment of the Femoral Neck. E-Dissertations of the National Academy of Surgery, 10, 014-019.

[13] Smith Petersen, M.N., Cave, E.F. and Vangorder, G.W. (1931) Intracapsular Fractures of the Neck of the Femur: Treatment by Internal Fixation. Arch Surg, 23, 715-759. https://doi.org/10.1001/archsurg.1931.01160110002001

[14] Judet, R., Judet, J., Launois, B. and Gubler, J.P. (1966) Trial of Experimental Revascularization of the Femoral Head. Revue de Chirurgie Orthopédique et Réparatrice de 1 Appareil Moteur, 52, 277-303.

[15] Papakostidis, C., Panagiotopoulos, A., Piccioli, A. and Giannoudis, P.V. (2015) Timing of Internal Fixation of Femoral Neck Fractures. A Systematic Review and Meta-Analysis of the Final Outcome. Injury, 46, 459-466. https://doi.org/10.1016/j.injury.2014.12.025

[16] Liporace, F., Gaines, R., Collinge, C. and Haidukewych, G.J. (2008) Results of Internal Fixation of Pauwels Type-3 Vertical Femoral Neck Fractures. Journal of Bone and Joint Surgery American-Volume, 90, 1654-1659. https://doi.org/10.2106/jbjs.g.01353

[17] Aminan, A., Gao, F., Fedoriv, W., et al. (2007) Vertically Oriented Femoral Neck Fractures: Mechanical Analysis of Four Fixation Techniques. Journal of Orthopaedic Trauma, 21, 544-548. https://doi.org/10.1097/bot.0b013e31814b822e

[18] Mille, F., Saadnia, R., Ferrier, M., et al. (2015) Fracture of the Femoral Neck and 
Triple Screwing Can We Predict Failure? Rev Chir Ortho-Traumato, 101, 219.

[19] Thein, R., Herman, A., Keden, P., Chechik, A. and Shazar, N. (2014) Osteosynthesis of Unstable Intracapsular Femoral Neck Fracture by Dynamic Locking Plate or Screw Fixation: Early Results. Journal of Orthopaedic Trauma, 28, 70-76. https://doi.org/10.1097/bot.0b013e3182a225fa

[20] Chevalleys, F., Krieg, M.A. and Yersin, B. (2001) Proximal Fractures of the Femur. Rev Med Switzerland, 3, Article ID: 21644. 